\title{
Sensorless AC Current Control with Backstepping Design for a PWM AC-DC Converter
}

\author{
B. Bourahla ${ }^{1}$, B. Mazari ${ }^{1}$, S. Moreau ${ }^{2}$, G. Champenois ${ }^{2}$ \\ ${ }^{1}$ University of Sciences and technology of Oran, Algeria \\ Faculty of Electrical engineering B.P 1505 El M'naouer, 31000 Oran-Algeria \\ ${ }^{2}$ LAII - University of Poitiers, 40 avenue du Recteur Pineau, 86022 Poitiers cedex, France \\ e-mail : boumediene2006_dz@yahoo.fr; mazari_dz@yahoo.fr; \\ sandrine.moreau@univ-poitiers.fr, gerard.champenois@univ-poitiers.fr
}

\begin{abstract}
In this paper, a novel sensorless AC current control scheme is proposed for the design of PWM AC-DC converter. This design strategy deals with nonlinear backstepping controllers and $\mathrm{AC}$ current observer to achieve the purpose of current following. In general, PWM AC-DC converter design requires $\mathrm{AC}$ current measurement to achieve control goals, the backstepping observer employed estimates the AC current, and then nonlinear controllers based on backstepping design algorithm are developed to realize the sensorless AC current for the PWM AC-DC converter system. The proposed control scheme is not only to stabilize the PWM AC-DC converter system, but also to drive the current tracking error to converge to zero asymptotically. Furthermore, some simulation results are shown to illustrate excellent performances of the nonlinear backstepping control design scheme applied to a PWM AC-DC converter.
\end{abstract}

Key words: Backstepping control; Backstepping observer; PWM AC-DC converter; sensorless.

\section{Introduction}

Three phase AC-DC converters are widely used in industrial applications. Static power converters are nonlinear in nature and consequently generate harmonics into the supply. As a result, the power factor of the converters is usually poor and varies with the load. Most electrical systems are designed on the fundamental frequency [10].

Many research results focusing on the control of AC-DC converters have been reported [1]-[10] such as the adaptive backstepping controller and the feedback linearization technique applied to control the output voltage of three phase AC-DC PWM converter [1]-[2] with and without LCL input filters [7].

Different nonlinear techniques were also applied to converters in electric power networks such as DC/DC series resonant converter and three-phase three-level neutral point clamped rectifier [4]-[5]-[6].

Nonlinear backstepping control [8]-[9]-[11] is a newly developed systematic design method. The most appealing point of it is to use the virtual control variable to make the high-order system simple and thus the final control outputs can be derived step by step through appropriate Lyapunov functions.

The design of PWM AC-DC converter systems, in general, requires input current for AC-DC converter measurement to achieve control targets, but lots of PWM AC-DC converter systems do not have AC current [3][12]-[13] or AC voltage [14]-[15] or DC voltage measurement devices. Eliminating $\mathrm{AC}$ current or $\mathrm{AC}$ or DC voltage sensors simplifies the structure of the driver system.

In this paper, with the proposed backstepping AC current observer, a nonlinear backstepping control design scheme is developed for the current tracking control of PWM ACDC converter that has exact model knowledge. The asymptotic stability of the resulting closed-loop system is guaranteed according to Lyapunov stability theorem. As a result, the proposed nonlinear backstepping control design without the use of current sensor is not only to stabilize the AC-DC converter system, but also to force the current tracking error to converge to zero asymptotically.

The remainder of this paper is organized as follows. In section 2, the dynamic model of a PWM AC-DC converter is introduced with some important system properties. The sensorless backstepping control scheme consisting of an AC current observer and current input controllers are developed in Section 3 for the purpose current tracking. The simulation results are illustrated in Section 4, and some concluding remarks are given in Section 5 .

\section{Mathematical model of PWM AC-DC converter}

Figure 1 represents the topology of the converter under study. The dynamic model of a PWM AC-DC converter can be described in the well known (d,q) frame through the Park transformation [1]-[2] as follows: 
$\dot{i}_{d}=-\frac{R}{L} i_{d}+\omega i_{q}+\frac{1}{L}\left(E_{d}-v_{d}\right)$

$\dot{i}_{q}=-\frac{R}{L} i_{q}-\omega i_{d}+\frac{1}{L}\left(E_{q}-v_{q}\right)$

$\dot{v}_{d c}=\frac{2}{3 C v_{d c}}\left(E_{d} i_{d}+E_{q} i_{q}\right)-\frac{v_{d c}}{C R_{L}}$

Where $i_{d}$ and $i_{q}$ are $(d, q)$ axis currents, $E_{d}$ and $E_{q}$ are $(d, q)$ axis source voltage, $v_{d c}$ is the DC output voltage, $v_{d}$ and $v_{q}$ are $(d, q)$ axis converter input voltage . $R$ and $L$ mean the line resistance and inductance, respectively, $R_{L}$ is the load resistance.

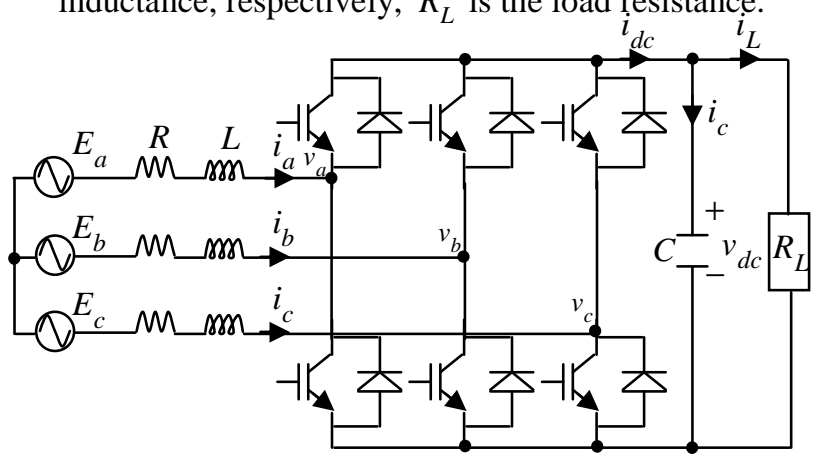

Fig. 1 AC/DC PWM converter topology

\section{Sensorless backstepping control}

Since the current measurement of the input AC-DC converter is usually unavailable, an AC current observer must be employed to estimate the actual AC current .Hence, the AC current estimation error is defined by:

$$
\begin{aligned}
& \tilde{i}_{d}=i_{d}-\hat{i}_{d} \\
& \tilde{i}_{q}=i_{q}-\hat{i}_{q}
\end{aligned}
$$

Where $\hat{i}_{d}$ is the estimate of $i_{d}$ and $\hat{i}_{q}$ is the estimate of $i_{q}$.

Now, we employ backstepping schemes to design the nonlinear controllers with the AC current observer, the backstepping design procedure consists of three steps:

Step 1: First of all, since the current $i_{d}$ must be forced to be zero, the first regulated variable is selected as

$e_{d}=i_{d}$

The derivative of (2) is computed as

$\dot{e}_{d}=\dot{i}_{d}=-\frac{R}{L} i_{d}+\omega i_{q}+\frac{E_{d}}{L}-\frac{v_{d}}{L}$

The first Lyapunov candidate $V_{l}$ is chosen as

$V_{1}=\frac{1}{2} e_{d}^{2}$

The derivative of (4) is computed as

$$
\begin{aligned}
& \dot{V}_{1}=e_{d} \dot{e}_{d} \\
& \dot{V}_{1}=-k_{l} e_{d}^{2}+e_{d}\left(k_{l} e_{d}-\frac{R}{L} i_{d}+\omega\left(\tilde{i}_{q}+\hat{i}_{q}\right)+\frac{E_{d}}{L}-\frac{v_{d}}{L}\right)
\end{aligned}
$$

At this point, the $d$-axis voltage control input $v_{d}$ can be selected by

$v_{d}=L\left(k_{l} e_{d}+\omega \hat{i}_{q}\right)+E_{d}$

Where $k$ is a positive design constant, so (5) becomes

$\dot{V}_{l}=-\left(k_{1}+\frac{R}{L}\right) e_{d}^{2}+\omega \tilde{i}_{q} e_{d}$

Step 2: the purpose of this control design is to achieve the reference voltage tracking, so the second regulated variable is denoted by

$e=v_{d c}-v_{d c r e f}$

Where $v_{d c r e f}$ is the reference signal of DC voltage. Hence, the derivative of (8) is calculated as

$\dot{e}=\frac{2}{3 C v_{d c}} E_{d} i_{d}+\frac{2}{3 C v_{d c}} E_{q} i_{q}-\frac{v_{d c}}{C R_{L}}-\dot{v}_{d c r e f}$

By defining the error variable $e_{q}=i_{q}-i_{\text {qref }}$, where $i_{\text {qref }}$ is the stabilizing function chosen as follows:

$$
i_{\text {qref }}=\frac{1}{E_{q}}\left(-E_{d} i_{d}+\frac{3 C v_{d c r e f}}{2}\left(\frac{v_{d c r e f}}{C R_{L}}+\dot{v}_{d c r e f}\right)\right)
$$

(9) can be rewritten as

$$
\begin{aligned}
\dot{e}= & \frac{2}{3 C v_{d c}} E_{q} e_{q}+\frac{2}{3 C v_{d c}} E_{q} i_{q r e f}+\frac{2}{3 C v_{d c}} E_{d} i_{d} \\
& -\frac{v_{d c}}{C R_{L}}-\dot{v}_{d c r e f} \\
\dot{e}= & -\frac{1}{C R_{L}} e+\frac{2}{3 C v_{d c}} E_{q} e_{q}
\end{aligned}
$$

With the choice of the second Lyapunov candidate

$$
V_{2}=\frac{1}{2} k_{2} e^{2}
$$

Where $k_{2}$ a positive design constant, the derivative of (12) is is computed as

$$
\begin{array}{r}
\dot{V}_{2}=k_{2} e \dot{e} \\
\dot{V}_{2}=-\frac{k_{2}}{C R_{L}} e^{2}+\frac{2 k_{2}}{3 C v_{d c}} E_{q} e_{q} e
\end{array}
$$

Step 3: The derivative of the given error variable $e_{q}$ is computed as

$$
\begin{aligned}
\dot{e}_{q}= & \dot{i}_{q}-\dot{i}_{q r e f} \\
\dot{e}_{q}= & -\frac{R}{L} i_{q}-\omega i_{d}+\frac{E_{q}}{L}-\frac{v_{q}}{L}+\frac{E_{d}}{E_{q}} \frac{d e_{d}}{d t}-\frac{3}{E_{q} R_{L}} v_{d c r e f} \dot{v}_{d c r e f} \\
& -\frac{3 C}{2 E_{q}} \dot{v}_{d c r e f}^{2}-\frac{3 C}{2 E_{q}} v_{d c r e f} \ddot{v}_{d c r e f} .
\end{aligned}
$$


Therefore, by following the choice of (4) and (12), the complete Lyapunov function candidate is selected as

$V=V_{1}+V_{2}+V_{3}+\frac{1}{2 \gamma_{1}} \tilde{i}_{d}^{2}++\frac{1}{2 \gamma_{2}} \tilde{i}_{q}^{2}$,

Where $\gamma_{1}, \gamma_{2}$ are the positive adaptation gains. From (7) and (13), (14), the derivative of (15) is computed as follows;

$$
\begin{aligned}
& \dot{V}=\dot{V}_{1}+\dot{V}_{2}+\dot{V}_{3}+\frac{1}{\gamma_{1}} \tilde{i}_{d} \dot{\tilde{i}}_{d}++\frac{1}{\gamma_{2}} \tilde{i}_{q} \dot{\tilde{i}}_{q} \\
& \dot{V}=-\left(k_{1}+\frac{R}{L}\right) e_{d}^{2}-\frac{k_{2}}{C R_{L}} e^{2}-k_{3} e_{q}^{2}+\frac{1}{\gamma_{1}} \tilde{i}_{d} \dot{\tilde{i}}_{d}++\frac{1}{\gamma_{2}} \tilde{i}_{q} \dot{\tilde{i}}_{q} \\
& +e_{q}\left(k_{3} e_{q}-\frac{R}{L} i_{q}-\omega i_{d}+\frac{E_{q}}{L}-\frac{v_{q}}{L}+\frac{E_{d}}{E_{q}} \frac{d e_{d}}{d t}\right. \\
& \left.-\frac{3}{E_{q} R_{L}} v_{d c r e f} \dot{v}_{d c r e f}-\frac{3 C}{2 E_{q}} \dot{v}_{d c r e f}^{2}-\frac{3 C}{2 E_{q}} v_{d c r e f} \ddot{v}_{d c r e f}\right) \\
& +\omega \tilde{i}_{q} e_{d}+\frac{2 k}{3 C v_{d c}} E_{q} e_{q} e \\
& \dot{V}=-\left(k_{1}+\frac{R}{L}\right) e_{d}^{2}-\frac{k_{2}}{C R_{L}} e^{2}-k_{3} e_{q}^{2}-\frac{R}{\gamma_{1} L} \tilde{i}_{d}^{2}-\frac{R}{\gamma_{2} L} \tilde{i}_{q}^{2} \\
& +e_{q}\left(k_{3} e_{q}-\frac{R}{L} \hat{i}_{q}-\omega \hat{i}_{d}+\frac{E_{q}}{L}-\frac{v_{q}}{L}+\frac{2 k_{2}}{3 C v_{d c}} E_{q} e\right. \\
& +\frac{E_{d}}{E_{q}}\left(-\frac{R}{L} \hat{i}_{d}+\omega \hat{i_{q}}+\frac{E_{d}}{L}-\frac{v_{d}}{L}\right)+\frac{E_{q}}{L}-\frac{v_{q}}{L}-\frac{3}{E_{q} R_{L}} v_{d c r e f} \dot{v}_{d c r e f}-\frac{3 C}{2 E_{q}} \dot{v}_{d c r e f}^{2} \\
& \left.-\frac{3 C}{2 E_{q}} v_{d c r e f} \ddot{v}_{d c r e f}\right)+\tilde{i}_{d}\left(\frac{1}{\gamma_{1}}\left(-\frac{R}{L} \hat{i}_{d}+\omega \hat{i}_{q}+\frac{E_{d}}{L}-\frac{v_{d}}{L}-\dot{\tilde{i}}_{d}\right)\right. \\
& \left.-\omega e_{q}-\frac{E_{d}}{E_{q}} \frac{R}{L}\right)+\tilde{i}_{q}\left(\frac{1}{\gamma_{2}}\left(-\frac{R}{L} \hat{i}_{q}-\omega \hat{i}_{d}+\frac{E_{q}}{L}-\frac{v_{q}}{L}-\dot{\tilde{i}}_{q}\right)\right. \\
& \left.+\omega e_{d}-\frac{R}{L} e_{q}+\frac{E_{d}}{E_{q}} \omega\right)
\end{aligned}
$$

At last in order to make the derivative of the complete Lyapunov function (16) is negative definite, the direct axis voltage control input and the voltage adaptation law are chosen as follows:

$$
\begin{aligned}
v_{q}= & L\left(k_{3} e_{q}+\frac{2 k_{2}}{3 C v_{d c}} E_{q} e-\frac{R}{L} \hat{i}_{q}-\left(\omega+\frac{E_{d}}{E_{q}} \frac{R}{L}\right) \hat{i}_{d}\right. \\
& +\frac{E_{q}}{L}-\frac{E_{d}}{E_{q}} k_{l} e_{d}-\frac{3}{E_{q} R_{L}} v_{d c r e f} \dot{v}_{d c r e f}-\frac{3 C}{2 E_{q}} \dot{v}_{d c r e f}^{2} \\
& \left.-\frac{3 C}{2 E_{q}} v_{d c r e f} \ddot{v}_{d c r e f}\right) \\
\hat{i}_{d}= & \frac{L}{(L+R)}\left(\omega \hat{i}_{q}+\frac{E_{d}}{L}-\frac{v_{d}}{L}-\left(\omega e_{q}+\frac{E_{d}}{E_{q}} \frac{R}{L}\right) \gamma_{1}\right)
\end{aligned}
$$

$$
\hat{i}_{q}=\frac{L}{(L+R)}\left(-\omega \hat{i}_{d}+\frac{E_{q}}{L}-\frac{v_{q}}{L}+\left(\omega e_{d}-\frac{R}{L} e_{q}+\frac{E_{d}}{E_{q}} \omega\right) \gamma_{2}\right)
$$

Therefore, substituting (18), (19) and (20) into (17), we are able to obtain

$$
\dot{V}=-\left(k_{1}+\frac{R}{L}\right) e_{d}^{2}-\frac{k_{2}}{C R_{L}} e^{2}-k_{3} e_{q}^{2}-\frac{R}{\gamma_{1} L} \tilde{i}_{d}^{2}-\frac{R}{\gamma_{2} L} \tilde{i}_{q}^{2}
$$

Clearly, $\dot{V}$ in (21) is negative definite, so it implies that the resulting closed loop system is asymptotically stable and, hence, all the error variables $e_{d}, e$ and $e_{q}$ and the estimation error $\dot{\tilde{i}}_{d}, \dot{\tilde{i}}_{q}$ will converge to zero asymptotically. Therefore, the $d$-axis current $\hat{i}_{d}$ will converge to zero and the DC voltage will converge to the reference output voltage for PWM AC-DC converter. In addition, because $e_{d}$ and $e_{q}$ can converge to zero, the estimated input current for AC-DC converter will converge to the actual real input current in the primary side of the converter.

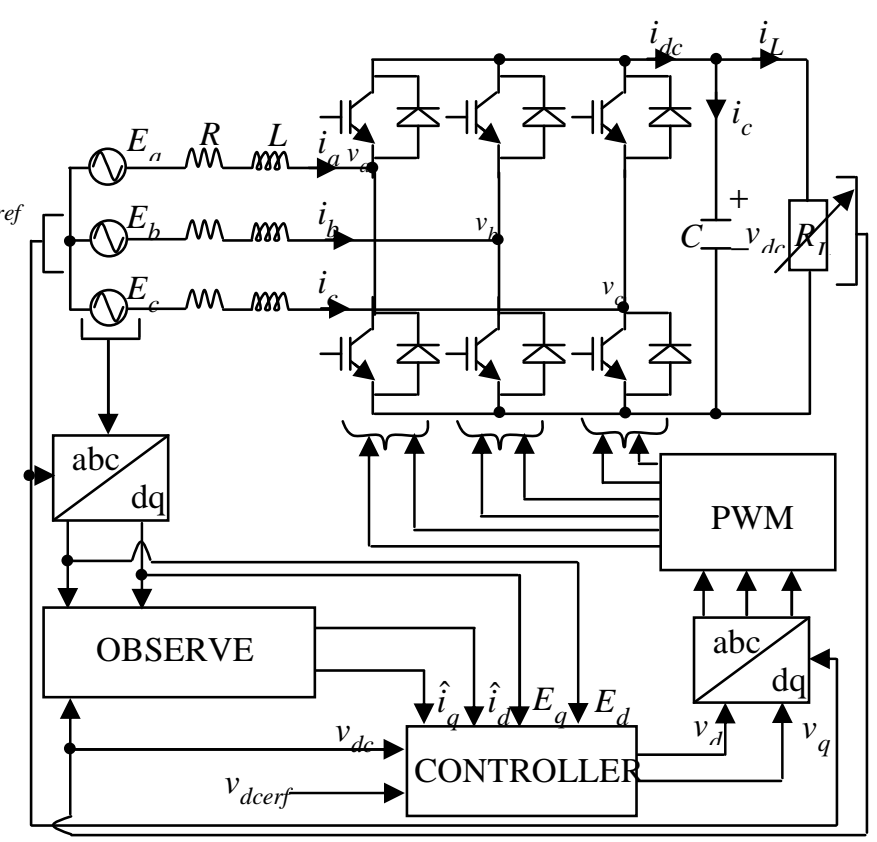

Fig. 2 The block diagram of AC current tracking design scheme

\section{Simulation results}

In our simulations, the system parameters and design constants of the PWM AC-DC converter are given in Tables I and II, respectively. 
Table I

PWM AC-DC Converter system parameters

\begin{tabular}{|l|l|}
\hline Supply's voltage and frequency & $220 \mathrm{~V}, 50 \mathrm{~Hz}$ \\
\hline Line's inductor and resistance & $0.1 \mathrm{mH}, 2 \mathrm{~m} \Omega$ \\
\hline DC link resistance & $20 \Omega$ \\
\hline Output capacitors & $370 \mu \mathrm{F}$ \\
\hline PWM carrier frequency & $1 \mathrm{kHz}$ \\
\hline
\end{tabular}

Table II

Control Design Constants

\begin{tabular}{|c|c|c|c|c|}
\hline$k_{1}$ & $k_{2}$ & $k_{3}$ & $\gamma_{1}$ & $\gamma_{2}$ \\
\hline 10000 & 1 & 70 & 1 & 1 \\
\hline
\end{tabular}

The voltage transient responses are chosen in the following two cases:

Case I: DC voltage reference changes from $250 \mathrm{~V}$ to $350 \mathrm{~V}$ and back to $250 \mathrm{~V}$.

Case II: load changes from $20 \Omega$ to $10 \Omega$.

The sensorless backstepping control with AC current observer is used in our comparative simulations. Fig.3 and 4 illustrate respectively the simulation results of voltage transient responses for DC voltage reference and for load changes.

The fig. $3 \mathrm{a}$ and fig. $4 \mathrm{a}$ show the voltage tracking response of the reference and real output DC voltage in the case of DC voltage reference and load changes and the error between them.

The fig. $3 \mathrm{~b}$ and fig. $4 \mathrm{~b}$ show the supply voltage and current in the primary side, the AC current estimated $i_{d}$ and $i_{q}$ and the error between the estimated currents and reference currents in cases I and II, respectively.

It can be seemed from fig. $3 \mathrm{a}$ and fig.4a that the actual DC voltage responses can track the reference DC voltage in the beginning when the reference DC voltage is an exponential lick signal. From the DC voltage tracking simulation results in fig. $3 \mathrm{~b}$ and fig. $4 \mathrm{~b}$, we can find that the estimated $\mathrm{AC}$ current with backstepping controllers have excellent performances.

The error between real DC voltage and reference DC voltage can converge to zero asymptotically. Therefore, the estimated $\mathrm{AC}$ current are able to converge to the references current. The direct axis current $i_{d}$ estimated is always forced to zero in order to correct and maintain to unity the primary power factor between source current and source voltage. The $q$ axis current $i_{q}$ estimated will approach a constant when the actual DC voltage reaches the reference DC voltage. Finally, we can find that the $(d, q)$ axis current errors between estimated ones and the references can converge to zero asymptotically.

From the comparison of DC voltage tracking simulation results shown in fig. $3 \mathrm{~b}$ and fig. $4 \mathrm{~b}$, it is clear that the estimated AC current with backstepping controllers have excellent performances. The direct axis current estimated is always forced to be zero as we have already expected.
From the simulation results, it is obvious that the proposed sensorless backstepping controllers are quite successful and efficient for the PWM AC-DC converter current tracking control.

\section{Conclusion}

In this paper, we have implemented and simulated the backstepping control and AC current observer which provide an efficient control design for both tracking and regulation, The resulting closed-loop system is guaranteed to be asymptotically stable, and the AC current tracking error and the $\mathrm{AC}$ current estimation error are able to converge to zero asymptotically according to Lyapunov stability theorem. In addition the simulation results have clearly illustrated that the proposed nonlinear backstepping controllers are quite effective and efficient for the PWM AC-DC converter current tracking control without the need of current sensors. The strategy control was very robust to uncertain parameters and gave a very high power factor and small ripple in the current line supply.

\section{References}

[1] D.C.Lee,G.M.Lee, and K.D.Lee, "DC-bus voltage control of three - phase AC/DC PWM converters using feedback linearization ,'IEEE Trans.Ind.Appl.,Vol.36,no.3, pp.826-833,May/Jan.2000.

[2] D.C.Lee, K.D.Lee, and G.M.Lee, "Voltage control of PWM converters using feedback linearization,"IEEE Trans.Appl.confe,.2, pp.1491-1496,.1998.

[3] D.C.Lee, and D.S.Lim, "AC voltage and current sensorless control of three-phase PWM rectifiers,"IEEE Trans.Power Electronics., Vol.17,no.6, pp.883-890,Nov.2002.

[4] L.Yacoubi,F.Fnaiech,L.A.Dessaint, and K.A.Haddad, "Adaptive nonlinear control of a three-phase three-level neutral point clamped rectifier,'Proc.IEEE.Ind.Appl.confe.US,.pp.619$625, .2001$

[5] L.Yacoubi,F.Fnaiech,K.A.Haddad, and L.A.Dessaint, "Input/Output feedback linearization control of a three-phase three-level neutral point clamped boost.rectifier,"Proc.IEEE.Ind.Appl.confe.US,.pp.626-631,.2001.

[6] L.Yacoubi, K.A.Haddad,F.Fnaiech,and L.A.Dessaint, "A DSPbased implementation of a new nonlinear control for a three-phase neutral point clamped rectifier,'IEEE.Trans.Ind.Elec.,Vol.52.no 1,pp.197-205,Feb 2005

[7] D.E.Kim,and D.C.Lee, "Feedback linearization control of threephase AC/DC PWM converters with LCL input filters,"IEEE.the $7^{\text {th }}$ International Converence on Power Elec.,pp.766-771,Oct 2226,2007.

[8] J.Zhou,and Y. Wang, "Adaptive backstepping speed controller design for a permanent magnet synchronous motor," Proceedings of the IEE Electron Power Application, Vol. 149,no. 2,pp. 165172,2002

[8] M.Krstié,I. Kanellakopoulos, and P.Kokotovié, nonlinear and adaptive control design, John Willey and Sons, Inc. 1995

[10] A.Allag,M.Y.Hammoudi,S.M.Mimoune, and M.Y.Ayad, "Adaptive backstepping voltage controller design for an PWM AC-DC converter," International Journal of Electrical and Power Engineering 1, 1,pp. 62-69, 2007

[11] S.S.Ke, and J.S.Lin,"Sensorless speed tracking control with backstepping design scheme for permanent magnet synchronous motors,"Proc.IEEE.Conf.Cont.Appl. Toronto,Canada,pp 487492,Aug 28-31,2005.

[12] C.T.Pan,"Modeling and analysis of a three phase PWM ac-dc converter without current sensor,"Proc.Inst.Elect.Eng.B,Vol.40,Mar.1993.

[13] W.C.Lee,D.S.Hyun, and T.K.Lee,“ A novel control method for three-phase PWM rectifier using single current sensor,'Proc.IEEE.PESC.Conf.,Charleston,SC,pp.515-520,1999. 
[14] T.Takeshita,T.Kobayashi, and N.Matsui, " A scheme of power source voltage sensorless three-phase PWM ac/dc converter, "Trans.IEE Jpn.,vol.114-D,no.12,pp.1211-1219,1994.

[15] T.Ohnuki,O.Miyashita,P.Lataire, and G.Maggetto," A three-phase PWM rectifier without voltage sensor,'Proc.EPE 97 Conf.,pp.2.881-2.886,1997.
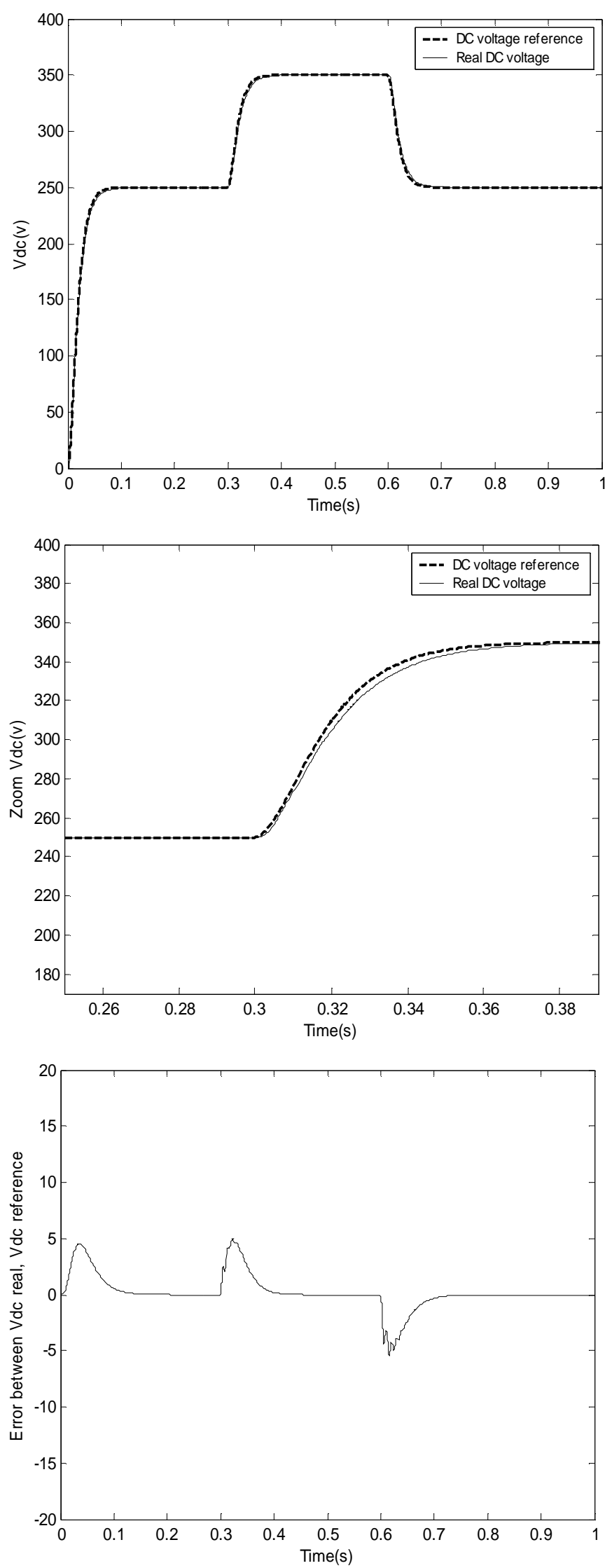

Fig. 3.a Voltage transient responses for dc-voltage reference changes
[16] B. Bourahla: "Commande Scalaire de la Machine Asynchrone en Temps Réel, Etude et Réalisation »

Master thesis, june $21^{\text {th }}, 2008$, USTO-MB, Oran, Algeria
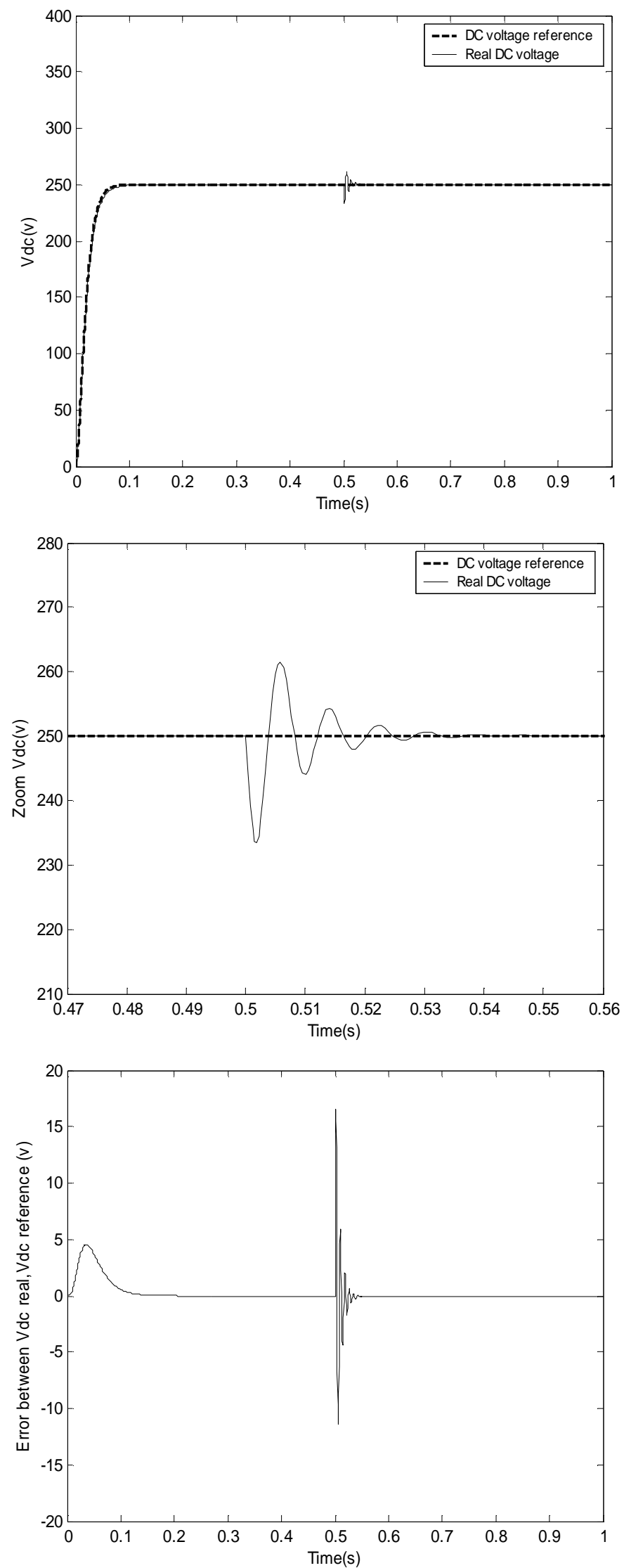

Fig. 4.a Voltage transient responses for load changes 

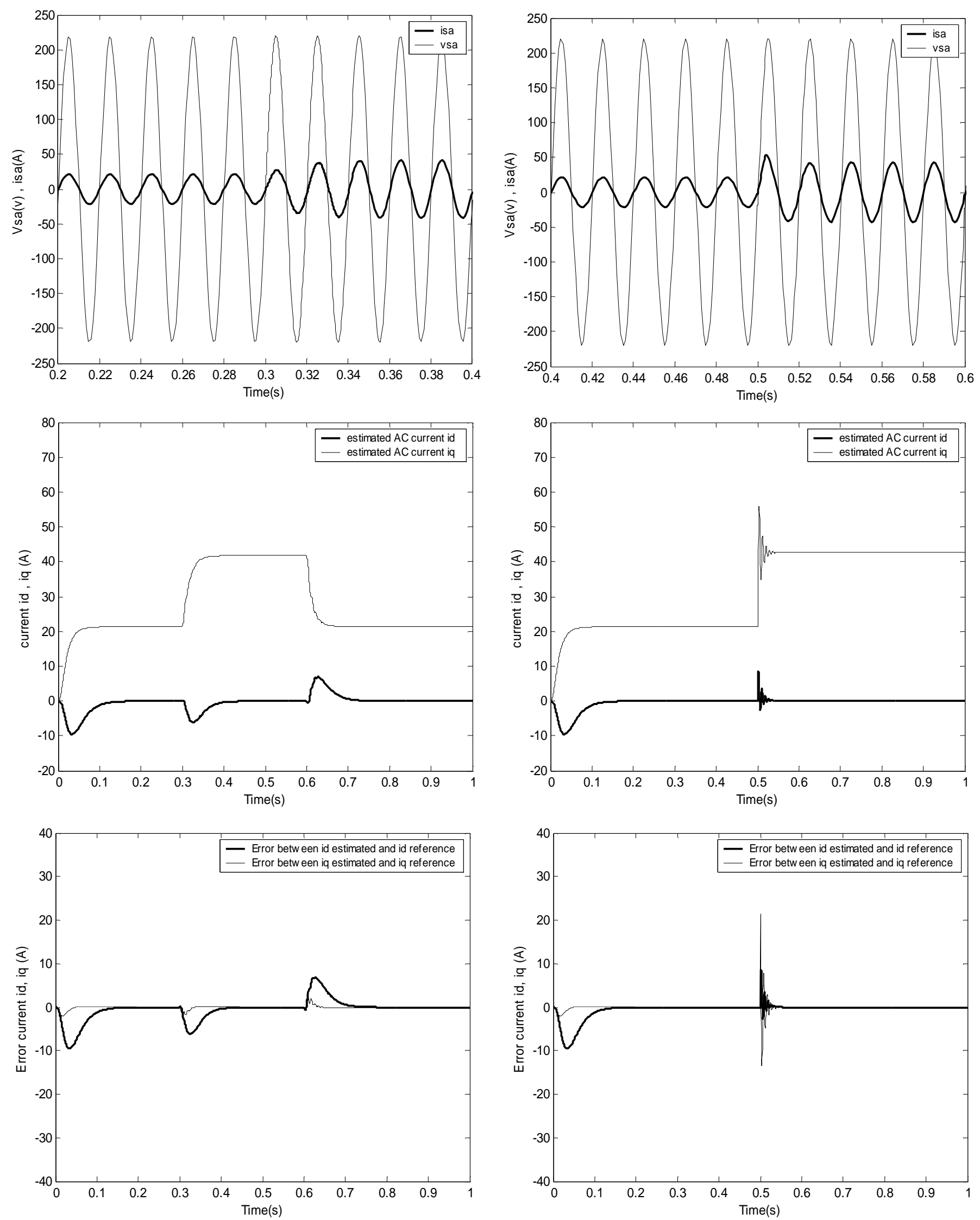

Fig. 3.b Voltage transient responses for dc-voltage reference changes

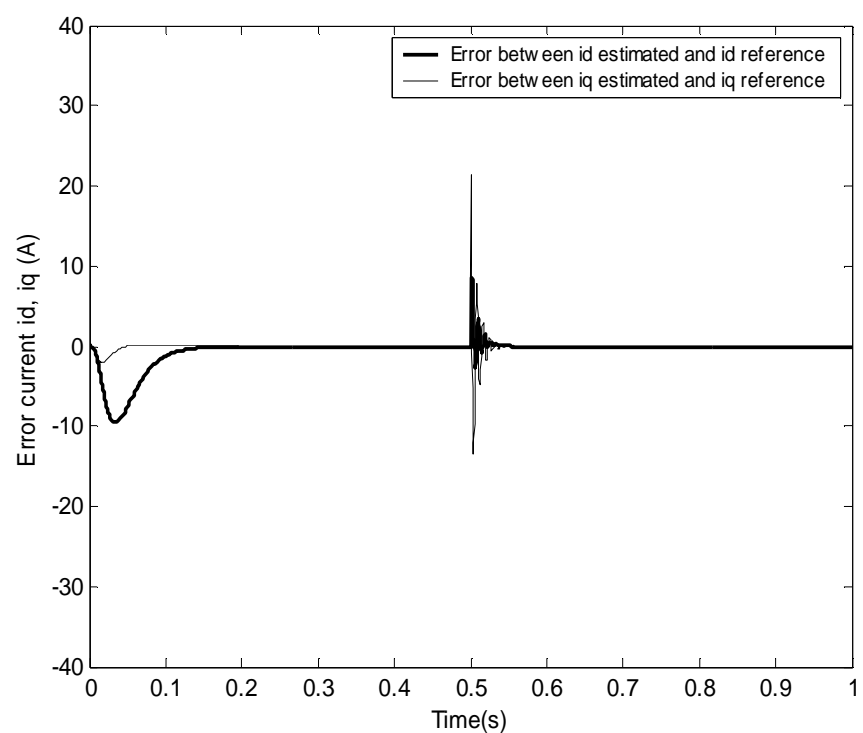

Fig. 4.b Voltage transient responses for load changes 